\title{
Editorial
}

\section{Hacia la universidad universal}

Discurso pronunciado por el rector del Politécnico Grancolombiano, institución universitaria, Pablo Michelsen Niño, en la ceremonia de graduación de profesionales en Comunicación Social - Periodismo, en Medios Audiovisuales y en Mercadeo y Publicidad, celebrada el miércoles 3 de marzo de 2010, en el Salón Conquistadores del Centro de Convenciones Gonzalo Jiménez de Quesada.

a palabra universidad proviene del sustantivo universo, que el DRAE define como "el conjunto de todas las cosas creadas", y por tanto corresponde a la idea de universalidad. Universidad con mayúscula inicial se refiere a una universidad en particular, por ejemplo, la Universidad de Oxford, en tanto que la universidad como término genérico puede corresponder a un universo de universidades, como la universidad bogotana, colombiana, latinoamericana, o mundial, y en tales casos comprende a todas las universidades del respectivo ámbito. En esta última acepción las universidades del mundo se conciben como una sola entidad, encargada de brindar educación universal a la humanidad, con base en la cultura universal, como misión fundamental.

El concepto de universidad, entendida como institución formada por un grupo de centros de enseñanza, llamados facultades, donde se imparte la enseñanza superior, existe desde el siglo XII, cuando fueron fundadas las universidades más antiguas del mundo, las universidades de Bolonia en Italia; de Oxford en Inglaterra, y de Salamanca en España.
Sin embargo, a lo largo de la historia las universidades no han hecho suficiente honor al concepto de universalidad, pues su cobertura ha sido muy limitada, prestando sus servicios de manera privilegiada a las élites socioeconómicas o intelectuales.

En el mundo del siglo XXI, con cerca de siete billones de habitantes en condiciones de desigualdad, que conforman una humanidad emproblemada y muy poco realizada, la universidad como concepto global siente intensamente el reto de corresponder mejor a la idea de universalidad, pues no solo las élites sino todos y cada uno de los seres humanos requieren de algún tipo de educación superior, así sea solamente para afrontar la vida a cualquier nivel, o para la realización del ser humano.

La universidad universal, incluso en el caso de las universidades de origen confesional o ideológico, tiene la misión y la obligación de brindar educación universal o integral, no solo para disciplinas o profesiones, sino para construir proyectos de vida exitosos, lo cual implica un gran conocimiento del ser humano, de la persona en 
sí misma, de la historia, de la familia, de la naturaleza, del entorno, de la sociedad, del mundo en proceso de globalización y de la cultura en general. Según un viejo refrán, la cultura es lo que le queda a uno después de que se le ha olvidado todo. Y esa educación integral tampoco puede limitarse a la simple actividad académica o intelectual sino que requiere además unos grandes componentes físico o deportivo, para fortalecer el cuerpo, y lúdico, para descansar y despejar la mente. La educación no es solo una acumulación de conocimientos universales sino también y especialmente un entrenamiento de la mente para razonar, para pensar e interrelacionar esos conocimientos, con el objeto de mejorar la vida humana en sociedad. En suma, la formación humanística es esencial en todo proceso educativo.

La Institución Universitaria Politécnico Grancolombiano lucha constantemente por la integralidad de su educación, mediante mecanismos como la división de todos sus programas académicos formales en cuatro bloques de asignaturas: el institucional, el de facultad, el de carrera y el opcional; y como la programación permanente de actividades deportivas, lúdicas y culturales, para contribuir al bienestar estudiantil.

En la universidad universal la educación es menos magistral que participativa por parte de todos los actores del proceso educativo, especialmente los estudiantes, en procura de logros y competencias. Es lo que pretende la Institución Universitaria Politécnico Grancolombiano por medio de políticas como la implantación de todas las materias en el software libre de educación virtual, llamado "Moodle", y el diálogo permanente entre profesores y estudiantes a través de este mismo dispositivo.
La calidad académica constituye una preocupación fundamental de la universidad universal. Desde que se estableció el sistema actual de aseguramiento de la calidad en Colombia, la Institución Universitaria Politécnico Grancolombiano ha recibido innumerables visitas de pares académicos del Ministerio de Educación y del Consejo Nacional de Acreditación (CNA), haciendo en todas ellas una digna presentación de su impresionante progreso como institución educativa. Los aspectos de cualificación que más dificultad presentan para las universidades son la infraestructura, la planta docente, la investigación y los egresados. A la infraestructura nos referiremos más adelante.

Para el presente semestre completamos 126 profesores de planta, con un crecimiento significativo. Estos profesores contribuyen decisivamente al desarrollo de los proyectos de investigación aplicada que se seleccionaron en reciente convocatoria con la participación de pares académicos tanto propios como externos, nacionales e internacionales. Dichos profesores también serán los orientadores del creciente número de proyectos de investigación formativa desarrollados por los estudiantes en el aula de clase. En cuanto a nuestros egresados, seguimos explorando maneras de mantenerlos unidos a su universidad, aunque nuestros resultados en este campo todavía dejan mucho que desear.

Gracias a estos esfuerzos todos nuestros programas académicos formales ya tienen sus registros calificados ante el Ministerio de Educación Nacional y están en proceso de autoevaluación de calidad, y dos de los más importantes, el de Mercadeo y Publicidad y el de Ingeniería de Sistemas, ya cuentan con su "acreditación de alta calidad" por parte del mismo ministerio, previo concepto favo- 
rable del Consejo Nacional de Acreditación (CNA).

Según la legislación colombiana, las funciones de la universidad son la docencia, la investigación y la proyección social o extensión. En este precepto, la universidad universal sabe que la investigación formativa, o sea la formación de mentes investigativas, es fundamental en todo proceso educativo pero, al mismo tiempo, es consciente de que no todos los niveles educativos, ni todos los programas académicos ni todos los estudiantes, necesitan o pueden darse el lujo de desarrollar investigación aplicada de alto nivel, pues la misión más importante de las universidades en el mundo es la formación de las personas para trabajar y crear empresas productivas. Muy pocas universidades en el mundo son especializadas en investigación o tienen presupuestos suficientes para realizar investigación aplicada de alto nivel. Por estas razones las funciones de investigación y proyección social son fundamentales en la universidad, pero por lo general son accesorias de la misión formativa.

La universidad universal tiene que educar para la internacionalización y para un mundo en proceso de globalización, en el que los medios de comunicación han ido borrando las fronteras culturales de los países, a pesar de que se mantengan los límites económicos y laborales.

En respuesta a este reto descomunal, la Institución Universitaria Politécnico Grancolombiano tiene toda una política de internacionalización. Hace algo más de tres años se vinculó a la red Whitney International University System, que actualmente cuenta con universidades e instituciones educativas afiliadas de Estados Unidos, Brasil, Colombia, Argentina, Chiley Panamá, y se seguirá exten- diendo por otros países. Esta red ha sido una fuente infinita de experiencias para nosotros. También formamos parte de otras redes internacionales, como la Red Latinoamericana de Cooperación Universitaria (RLCU), que han contribuido a profundizar y ampliar nuestro bagaje académico y nos han proveído oportunidades de movilidad internacional para nuestros estudiantes y profesores. Cada semestre entre 150 y 200 de nuestros estudiantes están viajando a desarrollar programas académicos en el exterior. En el semestre en curso tenemos 195 alumnos en 34 países.

En la universidad universal, por virtud de las Tecnologías de la Información y las Comunicaciones (TIC), los campus virtuales se irán haciendo más importantes que los campus físicos. No obstante, los campus físicos, ubicados en impresionantes edificios y en bellos y frondosos terrenos, han tenido enorme importancia en la historia de la universidad.

La Institución Universitaria Politécnico Grancolombiano tiene un bello campus principal en los cerros orientales de Bogotá, el cual se ha desarrollado con especial respeto por la ecología del medio ambiente que lo rodea. Como las posibilidades de construcción en todos los cerros orientales están suspendidas por razones jurídicas, cada cierto tiempo nos vemos en la necesidad de readecuar nuestras instalaciones. No por casualidad acabamos de terminar una nueva remodelación de diversas áreas, como las oficinas de las decanaturas, de las direcciones de departamentos académicos y de los profesores de planta, varias aulas, espacios de circulación, las áreas de bienestar universitario, las cafeterías y el centro de transmisión virtual vía satélite, entre otras. Durante la Semana Santa remodelaremos nuevamente la biblioteca principal. 
Recientemente ya nos vimos en la imperiosa necesidad de adquirir un valioso lote en la Calle 61 abajo de la Carrera $7^{\mathrm{a}}$, en el cual nos proponemos construir un Campus-Ciudad apropiado para operar en permanente conexión con el campus principal por medio de nuestro sistema de transporte. Posiblemente será una torre de siete pisos, a la cual podrán ingresar los buses que transportan a nuestra comunidad universitaria. Hace unas semanas trasladamos a este nuevo predio el terminal de transporte, pues las autoridades de la ciudad prohibieron el paradero de buses sobre la vía pública en la Calle 53.

Nuestro sistema de transporte también se encuentra en proceso de reestructuración, con la ayuda de una de las firmas transportadoras más importantes de la ciudad. Aunque en este momento está operando con buses provisionales, en los próximos tres meses contará con buses diseñados especialmente para nuestras necesidades, más fáciles de abordar y desabordar, y decorados con nuestra propia imagen institucional.

Todas estas soluciones son casi milagrosas en una ciudad tan caótica y tan deficientemente planeada como Bogotá. Ni la comunidad en general, ni las autoridades distritales se imaginan cuánto hemos sufrido por causa de las dificultades urbanísticas.

Pero en el complejo mundo actual la universidad universal no puede mantenerse enclaustrada en sus campus físicos, por bellos y poderosos que sean, sino que debe salir a buscar las necesidades educativas de la sociedad, para lo cual cuenta con las TIC, y con la cadena de formación por ciclos propedéuticos. En la época que vivimos ninguna universidad podrá sobrevivir sin apropiarse de las TiC.
La universidad universal debe ser inclusiva, no exclusiva. En un mundo de casi 7.000 millones de habitantes, que serán 9.000 millones en el año 2.050, cuando empezará a declinar el crecimiento demográfico y a aumentar la edad promedio de la población, no se puede aspirar a llevar a todas las personas a un campus universitario a cursar programas de educación presencial. Aunque siempre existirán universidades exclusivas, que reciben a personas de altos niveles intelectuales o económicos, la universidad universal tiene la posibilidad de prestar sus servicios a un número mucho mayor de las personas que la necesitan, adaptándose a varios niveles de exigencia académica y de costo económico.

La Institución Universitaria Politécnico Grancolombiano inauguró hace dos años su proyecto de educación virtual en alianza con Whitney International University System, por medio de un novedoso modelo pedagógico que combina los siguientes elementos:

- Transmisión vía satélite desde estudios especializados.

- Diseño curricular por logros y por competencias.

- Plataformas virtuales como el software libre de educación a distancia, llamado Moodle, o como Epic, que es de propiedad de la red Whitney.

- Asistencia tutorial permanente.

- Centros Locales de Aprendizaje distribuidos en distintas ciudades, en los cuales los estudiantes cuentan con aulas y centros de cómputo, participan en teleconferencias y realizan trabajo grupal con sus compañeros.

Estos elementos también nos sirven para seguir perfeccionando nuestra educación presencial, y hacerla más interactiva y parti- 
cipativa por parte de estudiantes, profesores y directivos académicos y administrativos.

Para el semestre en curso ya tendremos alrededor de 3.600 estudiantes en nuestro campus virtual y diecinueve Centros Locales de Aprendizaje en operación.

La Institución Universitaria Politécnico Grancolombiano igualmente se ha caracterizado por participar en casi todos los niveles de la cadena de formación. En la educación superior formal ofrece ciclos técnicos, tecnológicos, profesionales y de posgrado, por ahora en el nivel de especialización. En el campo de la educación no formal participa en la educación para el trabajo y el desarrollo humano mediante un conjunto de programas técnico-laborales que pueden cursarse autónomamente y que también le sirven para ofrecerlos en colegios de educación secundaria, en los últimos años de bachillerato clásico y en el ciclo medio técnico vocacional, como medio de articulación entre el bachillerato y la universidad. No olvidemos que la legislación vigente permite validar en la universidad conocimientos adquiridos en la educación informal.

También en el campo no formal la institución cuenta con un exitoso modelo de formación empresarial a la medida y con diversos cursos de educación continuada. Además, su filial Fundación Compuclub ha sido durante más de 25 años uno de los más grandes capacitadores en sistemas de información y uno de los más importantes aliados de capacitación de Microsoft en Colombia. Compuclub realiza la capacitación básica en sistemas de todos nuestros estudiantes de pregrado.

A mi juicio, existe consenso en la cultura universal en que la libertad es una de las facultades esenciales del ser humano, sin la cual no es posible su realización. Como lo sugerimos al comienzo de esta disertación, la universidad universal, aún en el caso de instituciones confesionales, debe ofrecer y explicar los conocimientos universales al educando, para que este, en ejercicio de su libertad, escoja libremente sus opciones de vida y de comportamiento.

Para esta elección de opciones se requiere un sistema axiológico de valores. La Institución Universitaria Politécnico Grancolombiano no es una institución confesional. No pertenece a ninguna religión o ideología pero, precisamente, porque las respeta a todas, siempre y cuando estén basadas en la buena fe. Pero la institución sí tiene y profesa un valor o principio fundamental que es satisfactorio para todas las religiones e ideologías y que de alguna manera engloba a todos los altos valores de la humanidad. Se trata del espíritu de bondad y amor al prójimo que, para que no se le dé solamente una interpretación religiosa, pero sin perjuicio de ella, prefiero denominar sentido de solidaridad, equidad, generosidad y amabilidad.

Este principio permite realizar un balance del bien y del mal, de lo bueno y de lo malo de la vida humana, con ayuda de la conciencia como rasero individual e íntimo, y de la justa aplicación de la ley, como convención social. La conciencia, simbolizada en el corazón de cada persona, constituye un juez implacable e ineludible, al cual tarde o temprano le tendremos que rendir cuentas.

Según el novelista inglés William Somerset Maugham, la bondad es la fuerza más poderosa del ser humano. El escritor estadounidense Henry David Thoreau sostenía que "la bondad es la única inversión que nunca quiebra". Yo he llegado a la conclusión de que es con base en el ejercicio de 
la bondad que se establecen las verdaderas categorías del ser humano.

Infortunadamente, es necesario tener en cuenta que el ser humano es un animal racional imperfecto, que se encuentra en una etapa incipiente de su evolución, cuya capacidad de ejercer la bondad o la solidaridad es todavía muy precaria. La humanidad no ha podido superar el dinero y los intereses materiales como su valor más determinante. Podríamos decir que el capitalismo es el peor sistema económico, sin que exista ninguno mejor, como lo decían Platón y Churchill respecto de la democracia, en razón de que la naturaleza humana no ha dado para un orden social superior. La bondad, el amor y el afecto son la "materia prima" del ser humano, pero al mismo tiempo son el insumo más escaso.

Creo que el espíritu de bondad o de solidaridad, como valor universal, puede ser el instrumento más valioso de la universidad universal.

Para finalizar, la universidad universal debe ocuparse no solamente de los problemas locales o particulares, sino de los universales, en especial de aquellos que amenazan con destruir la humanidad, como la pobreza, el deterioro del medio ambiente y, en general, el desarrollo socioeconómico insostenible. En un mundo tan desequilibrado e inequitativo, con 2.500 millones de pobres y 1.200 millones de indigentes, el ejercicio de la bondad y la solidaridad constituye el único medio verdadero de ser feliz.

Queridos estudiantes graduandos: los felicito de todo corazón por el esfuerzo que han realizado para culminar sus progra- mas académicos y confío en que los títulos que ustedes reciben hoy les abrirán todo un mundo de posibilidades de realización personal, familiar y profesional. Espero ser testigo de sus éxitos y de su contribución decidida al desarrollo económico y social de Colombia. Sigan contando siempre con el Politécnico Grancolombiano como su segundo hogar. Ahora los invito a continuar los programas de especialización complementarios de sus carreras profesionales. En esta noche tan especial los exhorto a que luchemos con coraje por establecer el equilibrio y la equidad en el mundo, por medio del sentido de solidaridad y generosidad.

En nombre de la institución y de los graduandos agradezco a sus padres, familiares $\mathrm{y}$ acudientes, pues somos conscientes de que sin su apoyo y sus desvelos no estaríamos entregándoles hoy a Colombia y a la comunidad internacional este selecto grupo de 283 nuevos profesionales, del cual la institución y yo personalmente nos sentimos orgullosos.

Dentro de pocos minutos tendré el privilegio de entregarle los Diplomas de Mercadeo y Comunicaciones de la International Advertising Association (IAA), la asociación de comunicadores, mercadotecnistas y publicistas más grande del mundo, a los graduandos de la carrera profesional en Mercadeo y Publicidad, que se gradúan con un promedio general de calificaciones igual o superior a 4.00 sobre 5.00 , a quienes congratulo de manera especial y con mi más profundo orgullo.

Pablo Michelsen Niño Rector 